\title{
Pelatihan Literasi Iklan Pada Ibu-Ibu PKK di RW 07 Mustikajaya Bekasi
}

\author{
Sri Rejeki ${ }^{1}$, Dwi Budi Srisulistiowati ${ }^{1, *}$ \\ ${ }^{1}$ Fakultas Ilmu Komputer; Universitas Bhayangkara Jakarta Raya; Jl. Raya Perjuangan No.81 \\ Margamula, Bekasi Utara, Jawa Barat, Indonesia; Telp: (021) 74716718; e-mail:, \\ sri.rejeki@dsn.ubharajaya.ac.id, dwibudi@dsn.ubharajaya.ac.id \\ * Korespondensi: e-mail: dwibudi@dsn.ubharajaya.ac.id
}

Submitted: 02/08/2021; Revised: 04/08/2021; Accepted: 06/08/2021; Published: 08/08/2021

\begin{abstract}
Advertising literacy is the ability to recognize, evaluate, and understand advertisements and other commercial messages. The freedom of the public when using a social media will have an impact on the lack of supervision of an information content that will be broadcast. Thus, errors arise from the information obtained so that it can trigger hoaxes. The existence of fake news circulating refers to certain themes or topics. The activity took place at RW 07 Mustikajaya, East Bekasi. Advertising literacy activities were carried out by two lecturers of the Faculty of Computer Science. The activity was divided into two activity sessions, namely Understanding Literacy and Hoax Applications. In practice, we carry out Community Service (PKM) as a manifestation of the Tridarma of higher education, and mothers fill out a list of questions before and after receiving material conducted in Google Classroom and in its implementation using Google Meet. To improve understanding, advertising literacy materials are equipped with one of the hoax applications, namely Hoax Buster Tools. With this training, participants can increase their knowledge as well as stimulate them to get ideas and take appropriate actions in filtering the information obtained.
\end{abstract}

Keywords: Advertising Literacy, Hoax Buster Tools, PKM

\begin{abstract}
Abstrak
Literasi iklan merupakan kemampuan untuk mengenali, mengevaluasi, serta memahami sebuah iklan dan pesan yang berbau komersial lainnya. Bebasnya masyarakat pada saat memanfaatkan suatu media sosial akan berimbas dengan kurangnya pengawasan dari suatu konten informasi yang akan ditayangkan. Sehinggal, muncul kekeliruan dari informasi yang didapat sehingga bisa memicu hoaks (berita palsu). Adanya berita bohong yang beredar lebih merujuk pada beberapa tema ataupun topik tertentu, Kegiatan berlangsung di RW 07 Mustikajaya Bekasi Timur. Kegiatan literasi iklan dilakukan oleh dua orang dosen Fakultas Ilmu Komputer. Dalam kegiatan tersebut dibagi menjadi dua sesi kegiatan yaitu Pengertian Literasi dan Aplikasi Hoax. Praktiknya kami melakukan Pengabdian Kepada Masyarakat (PKM) sebagai salah satu perwujudan Tridarma perguruan tinggi, serta ibu-ibu melakukan pengisian daftar pertanyaan (Assessment) sebelum dan sesudah menerima materi yang dilakukan di Google Classroom dan dalam pelaksanaannya menggunakan Google Meet. Untuk meningkatkan pemahaman, materi literasi iklan dilengkapi dengan salah satu aplikasi hoax yaitu Hoax Buster Tools. Dengan adanya pelatihan ini peserta dapat meningkatkan pengetahuan sekaligus sebagai stimulasi dalam mendapatkan ide dan melakukan tindakan yang tepat dalam menyaring informasi yang didapat.
\end{abstract}

Kata kunci: Literasi Iklan, Hoax Buster Tools, PKM 


\section{Pendahuluan}

Berbagai cara dapat dilakukan dalam memasarkan suatu produk hingga sampai ketangan konsumen, salah satunya yaitu dengan penggunaan iklan. Iklan dianggap sebagai alat promosi yang ampuh dalam memberikan informasi kepada konsumen. Beberapa iklan dari yang dipublikasikan secara tradisional melalui media cetak maupun secara modern melalui radio, televisi ataupun internet.

Iklan adalah sebuah produk budaya yang sekaligus berperan dalam membentuk budaya di masyarakat. Iklan atau pariwara (Sunaryo, Karo, \& Dita, 2018). Iklan adalah bentuk pesan dalam melakukan promosi benda seperti barang, jasa, tempat usaha ataupun saran yang di informasikan melalui media dengan anggaran sponsor dan ditujukan kepada masyarakat (Palupi \& Pambudi, 2006). Karena itu, iklan juga dapat mempengaruhi cara masyarakat yang tidak hanya sebagai kebutuhan namun juga sebagai gaya hidup. Gaya hidup merupakan pola dari kehidupan manusia di dunia yang bisa diapresiasikan dalam kegiatan, keinginan, dan usulan. Pola kehidupan merupakan aktualisasi keseluruhan dari seseorang pada saat berhubungan dengan habitatnya.

Literasi biasa disebut 'melek', yaitu yang mencontoh pada dengan kesanggupan untuk dapat membaca serta memahami teks (Virga, 2017). Literasi dapat dipahami sebagai suatu kesanggupan dalam hasil, memahami, dan menggunakan teks dalam cara yang sesuai dengan kebudayaan (membudaya). Literasi secara sederhana dapat didefinisikan yaitu mengerti abjad, keahlian dan kecakapan baca tulis kini yang semakin didalami dan disosialisaikan kepada masyarakat. Literasi media merupakan bentuk dari literasi, yang secara tidak langsung dapat juga tidak terlepas dari sebuah informasi (Aulia, 2018). Informasi merupakan salah satu hal yang paling penting dalam sebuah kehidupan manusia, dikarenakan dengan informasi manusia dapat melakukan berbagai macam hal didalam kehidupannya. Literasi juga semakin kompleks bila dikaitkan dengan perkembangan teknologi informasi yang semakin cepat. Padahal tidak semua informasi itu dapat berfaedah, beberapa hal yang tidak konstruktif atau bahkan berbahaya bagi membangun keadaban yang baik.

Literasi iklan yaitu kemampuan untuk mengenali, mengevaluasi, serta memahami sebuah iklan dan pesan yang berbau komersial lainnya (Malmelin, 2010). Mengenali lima elemen dasar dari literacy. Adapun elemen-elemen itu, yaitu 1) Sebuah pemahaman dari akibat suatu iklan, 2) Sebuah kesadaran tentang suatu proses dari iklan, 3) Strategi untuk mengevaluasi serta mendiskusikan sebuah pesan iklan, 4) Sebuah pemahaman tentang isi iklan sebagai sebuah teks yang memberikan ide ke dalam kebudayaan dan kehidupan setiap individu. 5) Kemampuan untuk menikmati, memahami, dan menghargai isi iklan (Virga, 2017). Dengan kata lain, literasi iklan ditampilkan dalam suatu hubungan sosial berbasis teks iklan tertentu. Disini iklan dijadikan sebuah media dalam penyampaian teks itu sendiri.

Para pengguna internet (netizen) melihat media sosial yang mereka gunakan layaknya suatu ruangan privat (Nasrullah, 2014). Adapun informasi bisa diuraikan keaktifannya serta tidak lagi pasif seperti dalam alat tradisional lainnya. User dapat andil secara aktif dan sekalian 
memiliki seluruh kendali dalam menghasilkan sesuatu, mendistribusikan, dan melakukan diskusi serta komunikasi di alat publik terkait dengan pesan yang saling dikirim-terimakan. Dengan kata lain, user berhak mengakses media sosial yang ada pada mereka sehingga user condong dapat memberikan informasi yang dianggap penting untuk user lainnya (Herawati, 2016).

Bebasnya masyarakat pada saat memanfaatkan suatu media sosial akan berimbas dengan kurangnya pengawasan dari suatu konten informasi yang akan ditayangkan. Sehingga, muncul kekeliruan dari informasi yang didapat sehingga bisa memicu hoaks (berita palsu). Adanya hoaks yang beredar lebih memfokuskan pada beberapa tema ataupun topik tertentu, seperti mengenai isu sosial politik, permasalahan SARA, serta isu-isu kesehatan. Dalam hal tersebut, sekecil apapun gosip, tetapi menfokuskan pada berita bohong atau hoaks, misinformasi, maupun disinformasi, maka selanjutnya akan memicu konflik dan beberapa permasalahan lainnya dalam ranah publik. Hoaks pada dasarnya dimaknai sebagai informasi palsu yang sengaja diciptakan dengan tidak dapat dipertanggungjawabkan kebenarannya. Selanjutnya, hoaks juga melambangkan sebagai pesan yang tidak penuh dengan informasi yang informatif, melainkan lebih kepada pesan berita yang tidak benar, tidak sesuai kenyataan, serta bersifat bohong. Salah satu ciri khas dari hoaks adalah susunan kalimat yang cenderung bombastis dan hiperbola. Munculnya hoaks atau berita bohong secara dasar turut diatur dan dikelola dalam UU Nomor 11 Tahun 2008 tentang Informasi dan Transaksi Elektronik (ITE). Dalam teknisnya, ketentuan ini salah satunya bertujuan untuk mengelola dan mengantisipasi agar tidak muncul sejumlah hoaks yang beredar di masyarakat, terlebih kebohongan yang memunculkan ujaran kebencian. Mengingat kondisi Indonesia dengan konteks dan lingkungan masyarakat yang plural, dengan keragaman budaya ataupun SARA sebagai bagian dari satu kesatuan bangsa sehingga tidak jarang jika kemudian perbedaan dan keragaman ini justru membentuk Indonesia menjadi beraneka, tetapi sekaligus mampu menimbulkan konflik pertentangan yang dipicu oleh adanya berita bohong (hoaks).

Maraknya hoaks yang muncul di lingkungan masyarakat turut menjadi perhatian bagi Fakultas IImu Komputer (Fasilkom) Universitas Bhayangkara Jakarta Raya sebagai salah satu bagian yang erat kaitannya dengan studi informatika. Dalam konteks ini, Prodi Informatika melalui programnya berupaya untuk melaksanakan Tri Dharma Perguruan Tinggi dalam sejumlah implementasi kegiatan, baik yang berkenaan dengan pengajaran, penelitian, maupun pengabdian kepada masyarakat. Maka dari itu, mengingat sejumlah fenomena yang muncul terkait dengan banyak hoaks dan pemberitaan bohong yang ada di masyarakat. Fasilkom memberikan pelayanan dalam bidang pengabdian kepada masyarakat melalui pelatihan literasi iklan.

Literasi digital pada dasarnya berangkat dari bagaimana penggunaan media oleh masyarakat. Selain itu, adanya perkembangan media dan teknologi juga turut mempengaruhi bagaimana kecenderungan pemakaian ataupun penggunaan media oleh publik. Dalam konteks ini, muncul adanya pengaruh disrupsi media yang selanjutnya mengubah manusia dalam 
perilaku time series menjadi real time. Data yang diperoleh melalui perkembangan teknologi cenderung akan diolah dalam big data serta dapat diolah secara masif dan cepat. Masyarakat turut hidup dalam asset-aset konsumtif yang dipandang secara terbuka dan mampu digunakan secara bersama, saling berbagi serta berkolaborasi, tanpa harus memiliki sumber daya sendiri. Hal ini tampak berbeda dengan teknologi masa lalu yang cenderung harus membutuhkan waktu dalam pengolahannya (Sanna, Serafin, \& Maganetti, 2011). Salah satu bentuk filter antisipasi digital yang dapat dilakukan oleh masyarakat adalah dengan menggunakan Hoax Buster Tools. Hoax Buster Tools (Surakarta, 2020). Digunakan sebagai salah satu perangkat berbasis digital yang diperkenalkan untuk mengecek serta mengklarifikasi informasi, apakah informasi yang saling dikirim - terimakan adalah informasi yang sebenarnya atau justru merupakan hoaks atau berita bohong. Melalui perangkat ini, para lbu - ibu PKK yang menjadi peserta pengabdian diharapkan mampu teredukasi untuk selanjutnya menyebarkan informasi yang baik dan aktual kepada pengguna media yang lainnya.

\section{Metode Pelaksanaan}

Pendekatan kuantitatif dan kualitatif dalam sebuah penelitian, pada umumnya dibedakan dari sumbernya. Paradigma ilmiah yang bersumber dari pandangan positivisme menjadi rujukan dari paradigma penelitian kuantitatif. Sedangkan paradigma ilmiah yang bersumber dari pandangan fenomenologis, menjadi dasar dari pijakan pendekatan kualitatif. Kedua pendekatan ini mempunyai kelebihan dan kekurangan sehingga tidak jarang dipakai kedua-duanya oleh para peneliti dalam sebuah mixed methodology (Brannen, 2005). Dilihat dari instrumen penelitian yang menjadi alat pengumpulan data serta analisis, penelitian kualitatif banyak menggunakan data yang bersifat deskriptif seperti daftar wawancara, laporan dari hasil pengamatan dilapangan, transkrip - transkrip pembicaraan, dan catatan-catatan pengamatan. Laporan disusun dari sebuah rangkuman semua sumber - sumber tersebut dengan dukungan teori yang ada, menjadi uraian analisis. Tahap analisis dalam pendekatan ini sudah dimulai sejak penelitian dan data pertama telah diperoleh. Sedangkan penelitian kuantitatif menggunakan angket dan data - data yang berupa angka, tabulasi, perhitungan-perhitungan menggunakan sejumlah metode analisis matematik/statistik yang hasilnya menjadi dasar pijakan untuk mengambil keputusan atau kesimpulan. Data dari pendekatan kuantitatif lebih banyak berbentuk angka dan tabel. Sementara itu, tahap analisis hanya dapat dilakukan jika data telah terkumpul dengan lengkap dan tersaji dalam tabulasi yang siap diolah secara statistic (Slevitch, 2011).

Literasi Iklan dilaksanakan oleh Dosen Fasilkom Universitas Bhayangkara Jakarta Raya. Kegiatan berlangsung di RW 07 Mustikajaya Bekasi Timur. Kegiatan literasi iklan dilakukan oleh dua orang dosen Fasilkom. Dalam kegiatan tersebut dibagi menjadi dua sesi kegiatan yaitu Pengertian Literasi dan Aplikasi Hoax.

Praktik pelatihan literasi iklan dimulai dengan penyampaian tujuan melakukan Pengabdian Kepada Masyarakat sebagai salah satu perwujudan tridarma perguruan tinggi. 
Kemudian dilanjutkan dengan melakukan pengisian daftar pertanyaan (Assessment Awal) sebelum menerima materi pengabdian kepada masyarakat yang dilakukan di Google Classroom. Kemudian pemaparan materi dengan cara presentasi materi literasi ikan. Materi disampaikan dengan teknik penyampaian dua arah dengan menggunakan Google Meet. Tujuannya agar materi literasi iklan dapat diterima oleh ibu-ibu RW 07 Mustikajaya Bekasi dengan baik. Untuk meningkatkan pemahaman, materi literasi iklan dilengkapi dengan salah satu aplikasi hoax yaitu Hoax Buster Tools. Dalam aplikasi hoax ini dapat diketahui apakah iklan ini palsu atau tidak, sehingga dapat mempermudah ibu-ibu dalam menyaring sebuah informasi. Setelah pemaparan materi diberikan dilanjutkan dengan melakukan pengisian daftar pertanyaan (Assessment Akhir) setelah menerima materi pengabdian kepada masyarakat yang dilakukan di Google Classroom. Materi literasi iklan yang disampaikan berkaitan dengan pengertian literasi, tujuan literasi, manfaat literasi, jenis literasi, prinsip literasi, aplikasi hoax buster tools dan diskusi interaktif.

\section{Hasil dan Pembahasan}

Kegiatan ini dilaksanakan pada Hari Sabtu, 31 Juli 2021 secara daring di rumah masing-masing dan berlangsung pukul 09.00 - 12.00 WIB dengan menggunakan aplikasi Google Meet. Sebelum acara dimulai lbu - ibu diarahkan untuk masuk ke Google Classroom dan mengisi Assesment Awal (pretest) untuk mengukur tingkat pengetahuan mereka tentang iklan dan media sosial. Selanjutnya mereka mendengarkan Pelatihan literasi iklan ini di Google Meet yang kami berikan. Setelah selesai penyampaian materi, tidak lupa juga ibu-ibu kami arahkan untuk mengisi Assesment Akhir (post test) di Google Classroom. Banyaknya peserta yang mengikuti kegiatan ini ada sebanyak 20 orang, yaitu para ibu-ibu PKK RW 07 Mustikajaya Bekasi. Selama kegiatan berlangsung, para peserta diminta untuk mematikan mikrofon agar tidak mengganggu proses acara.

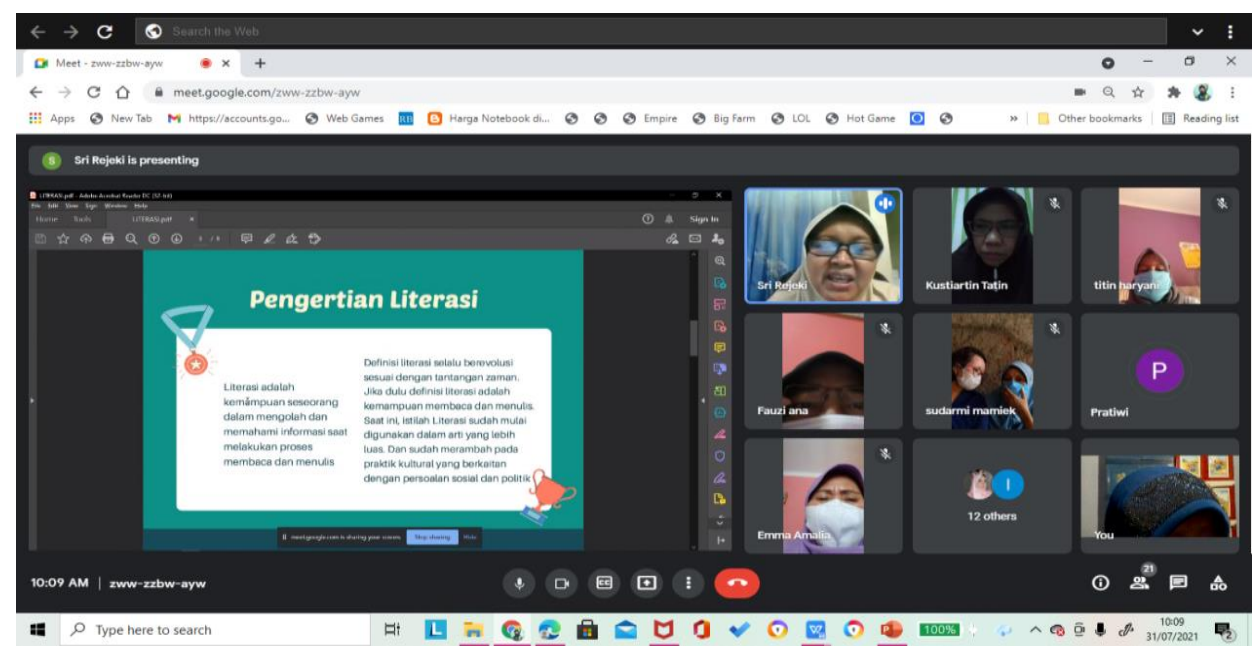

Sumber: Hasil Pelaksanaan (2021)

Gambar 1. Tampilan Google Meet Presentasi Sri Rejeki 
Acara diisi oleh narasumber yaitu dari dua orang dosen dari program studi Informatika, Universitas Bhayangkara Jakarta Raya, yaitu Sri Rejeki, S.Kom., M.M. dan Dwi Budi Srisulistiowati, S.Kom., M.M. Narasumber mempersiapkan materi terkait tema yang diusung, yaitu tentang Literasi Iklan dan Aplikasi Hoax.

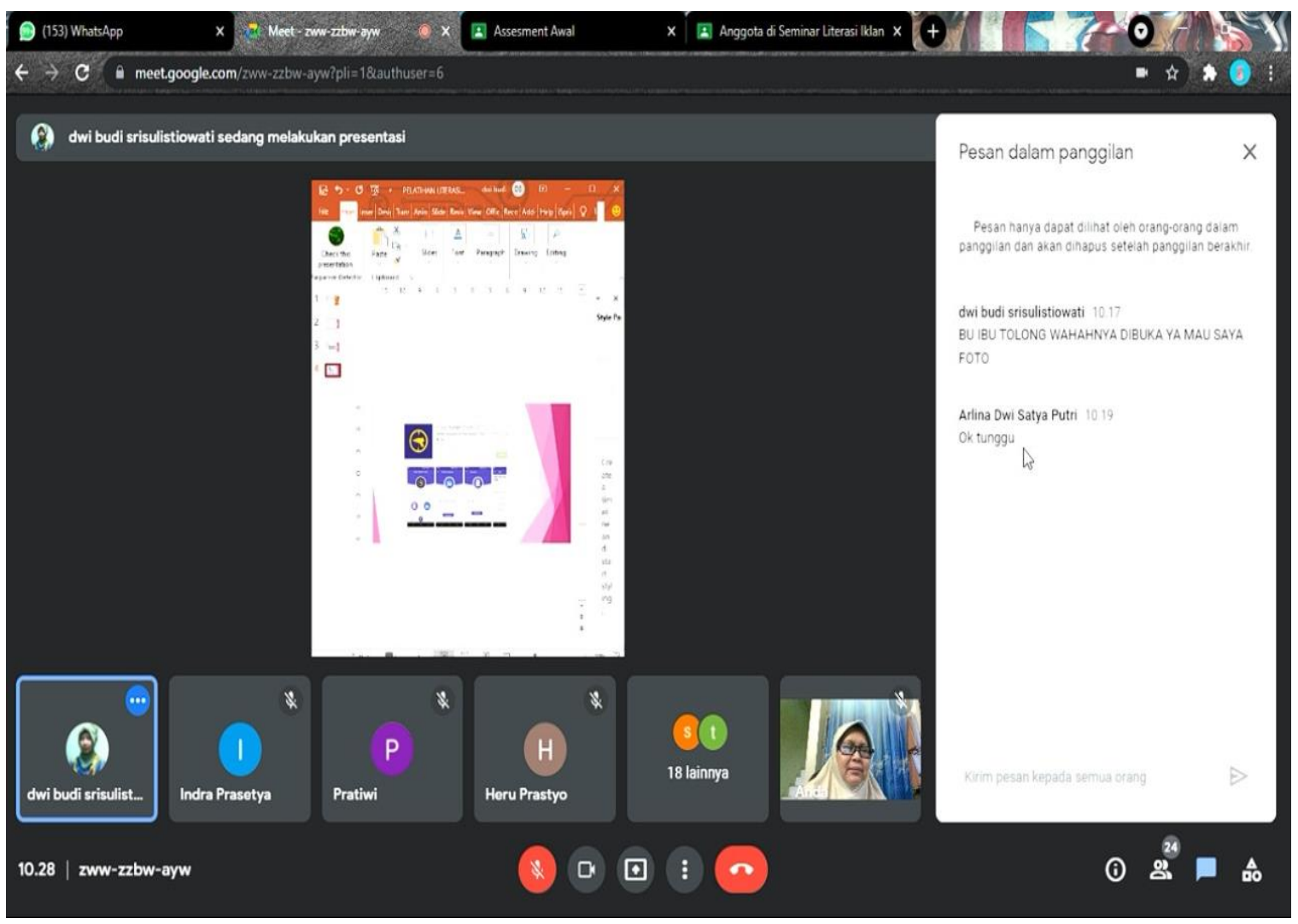

Sumber: Hasil Pelaksanaan (2021)

Gambar 2. Tampilan Google Meet Presentasi Dwi Budi Srisulistiowati

Gambar 1 dan Gambar 2 menjelaskan mengenai Presentasi 2 narasumber yaitu Sri Rejeki dan Dwi Budi Srisulistiowati, yang dilaksanakan dengan menggunakan Aplikasi Google Meet, yang link aksesnya kami berikan sebelum acara berlangsung.

Penggunaan Hoax Buster Tools pada dasarnya tergolong mudah. Dalam hal ini, perangkat Hoax Buster Tools dapat diunduh melalui Playstore dan dapat tersinkron dengan Google, terutama bagi para pengguna gawai berbasis Android.

Gambar 3 dan gambar 4 merupakan tampilan menu dan beberapa fasilitas dalam perangkat Hoax Buster Tools. Terkait hal ini, para ibu-ibu PKK yang menjadi peserta pengabdian diajari bagaimana menggunakan perangkat tersebut, mulai dari mengunduh perangkat, memasukkan beberapa kata kunci, ataupun melakukan pengecekan dan verifikasi pada beberapa informasi gambar iklan. Dalam kegiatan ini, peserta pengabdian terlihat antusias dan aktif dalam berpartisipasi. Selain merupakan hal baru, pengenalan dalam penggunaan perangkat Hoax Buster Tools ini juga merupakan alternatif yang menurut peserta bermanfaat dan mampu membantu mereka dalam mengantisipasi kemunculan hoaks. 


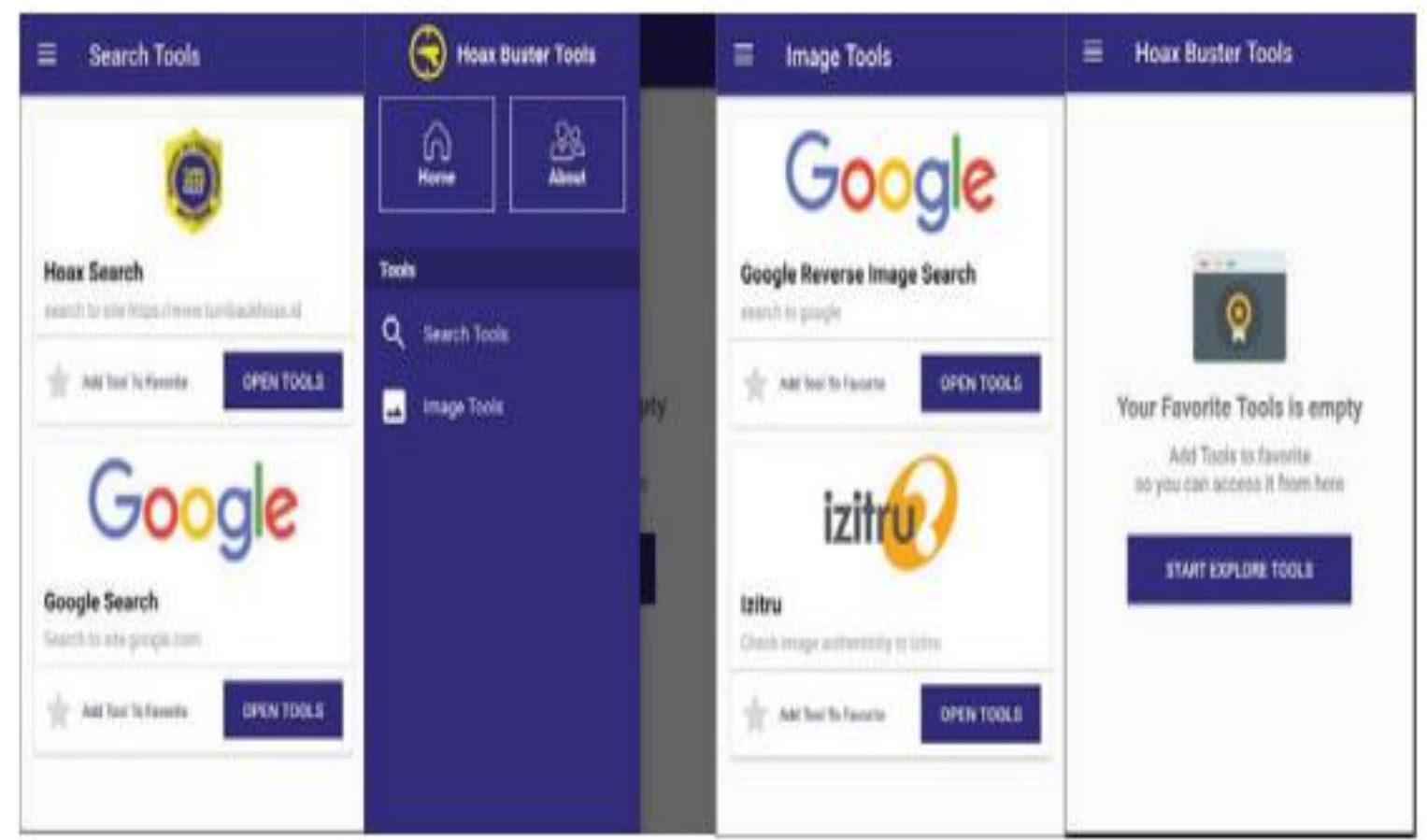

Sumber: Hasil Pelaksanaan (2021)

Gambar 3. Tampilan Hoax Buster Tools

Gambar 4 meanmpilkan hasil menu pencarian dan verifikasi dari aplikasi hoax buster tools.

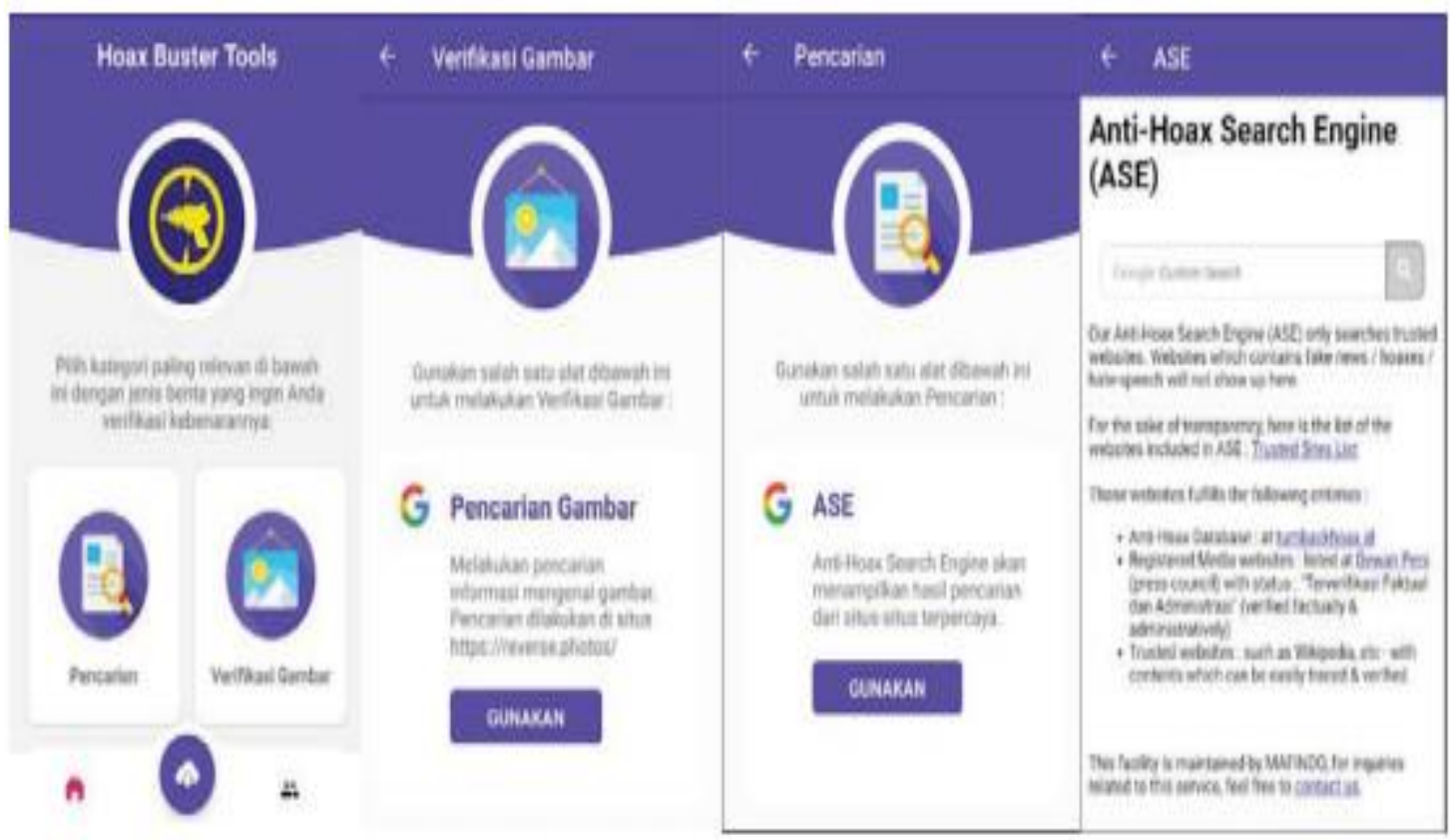

Sumber: Hasil Pelaksanaan (2021)

Gambar 4. Tampilan Menu Pencarian dan Verifikasi dalam Menu Hoax Buster Tools

Berikut ini assesment awal dan assesment akhir yang harus diisi oleh ibu-ibu PKK RW 07, yang dapat diakses di Google Classroom. 
Tabel 1. Assesment Awal dan Assesment Akhir

\begin{tabular}{|c|c|c|c|c|c|}
\hline No. & Pertanyaan & $\begin{array}{l}\text { Tidak } \\
\text { Mampu/ Tau }\end{array}$ & $\begin{array}{l}\text { Cukup } \\
\text { Mampu/ Tau }\end{array}$ & $\begin{array}{l}\text { Mampu/ } \\
\text { Tau }\end{array}$ & $\begin{array}{l}\text { Sangat } \\
\text { Mampu/ Tau }\end{array}$ \\
\hline 1. & $\begin{array}{l}\text { Apakah Anda mampu } \\
\text { mengoperasikan komputer? }\end{array}$ & & & & \\
\hline 2. & $\begin{array}{l}\text { Apakah Anda mampu mengunakan } \\
\text { internet? }\end{array}$ & & & & \\
\hline 3. & $\begin{array}{l}\text { Apakah Anda mengetahui apa itu } \\
\text { Medsos? }\end{array}$ & & & & \\
\hline 4. & $\begin{array}{lll}\text { Apakah } & \text { Anda } & \text { mampu } \\
\text { menggunakan salah satu Medsos ? }\end{array}$ & & & & \\
\hline 5. & $\begin{array}{l}\text { Apakah Anda mengetahui apa itu } \\
\text { Iklan? }\end{array}$ & & & & \\
\hline 6. & $\begin{array}{l}\text { Apakah Anda mampu Memprotek } \\
\text { Iklan yang tidak bagus? }\end{array}$ & & & & \\
\hline 7. & $\begin{array}{l}\text { Apakah Anda mengetahui apa itu } \\
\text { literasi ? }\end{array}$ & & & & \\
\hline 8. & $\begin{array}{l}\text { Apakah Anda mampu memilah } \\
\text { literasi ? }\end{array}$ & & & & \\
\hline 9. & $\begin{array}{l}\text { Apakah Anda mengetahui situs } \\
\text { literasi ? }\end{array}$ & & & & \\
\hline 10. & $\begin{array}{l}\text { Apakah anda mengetahui apa itu } \\
\text { Hoax Buster Tools? }\end{array}$ & & & & \\
\hline
\end{tabular}

Sumber: Hasil Pelaksanaan (2021)

Berdasarkan hasil assesment awal dan assesment akhir diperoleh peningkatan pemahaman peserta terkait materi kegiatan Literasi Iklan dan Aplikasi Hoax sebesar $40 \%$ dan $30 \%$. Hal ini cukup menunjukkan adanya peningkatan pemahaman peserta terhadap tema yang diusung, yang mana akan berguna bagi ibu-ibu PKK RW 07 Mustikajaya Bekasi. Dengan adanya kegiatan ini, penulis berharap para ibu-ibu PKK RW 07 Mustikajaya Bekasi dapat mengaplikasikannya dalam kehidupan.

Di akhir kegiatan setelah pemaparan materi dilanjutkan dengan diskusi dan pengisian form assessment dilanjutkan dengan sesi foto bersama antara narasumber dengan peserta kegiatan pelatihan. Gambar 5 menampilkan sesi foto bersama.

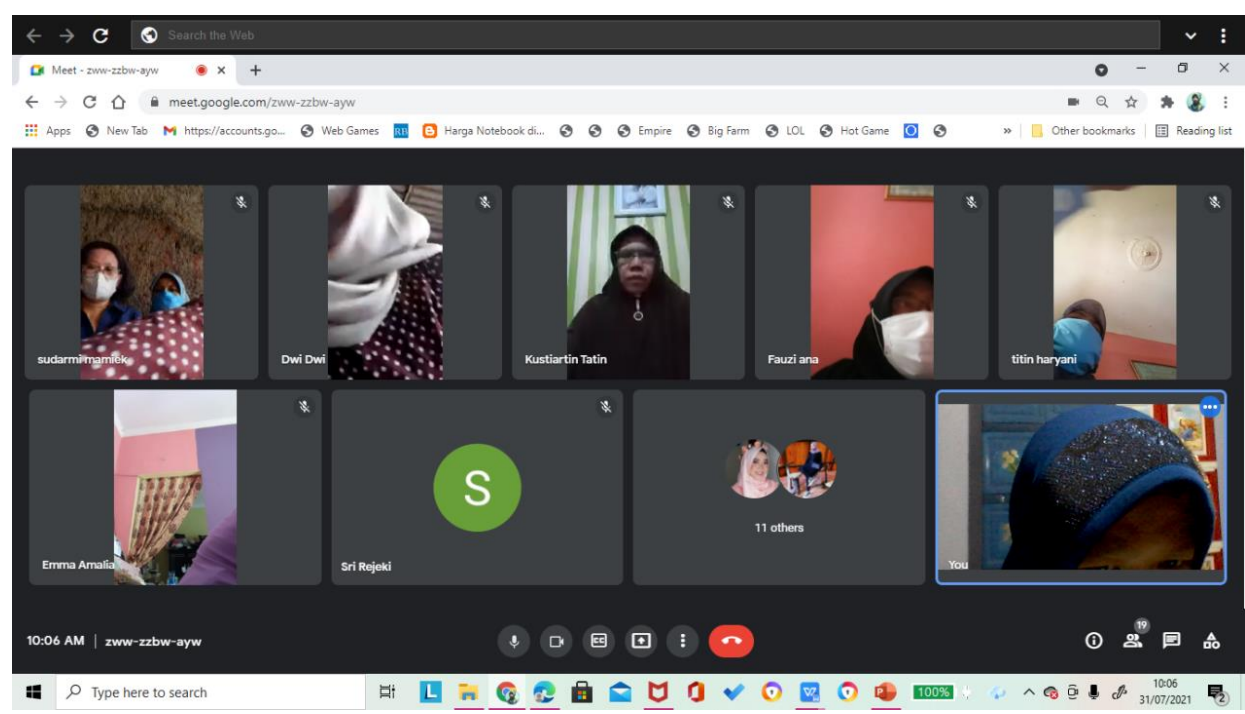

Sumber: Hasil Pelaksanaan (2021)

Gambar 5. Dokumentasi Foto Bersama 


\section{Kesimpulan}

Adanya pelatihan yang mengusung tema "Pelatihan Literasi Iklan Pada ibu-ibu PKK di RW 07 Mustikajaya Bekasi", peserta dapat meningkatkan pengetahuan sekaligus sebagai stimulasi agar peserta pelatihan lebih kreatif dalam mendapatkan ide dan melakukan tindakan yang tepat dalam menyaring informasi yang didapat. Berdasarkan hasil evaluasi setelah kegiatan berlangsung, saran yang dapat diberikan adalah perlu diadakan lagi kegiatan lanjutan yang temanya semakin mengerucut sehingga pemahaman yang diperoleh bisa lebih mendalam.

\section{Ucapan Terima Kasih (Opsional)}

Terima Kasih Untuk LPPMP yang sudah Mendanai PKM internal sehingga PKM ini bisa diselesaikan.

\section{Daftar Pustaka}

Aulia, D. M. (2018). Dampak Literasi Media Digital di Kalangan Mahasiswa. Kompasiana. Retrieved from https://www.kompasiana.com/dyahmaghifiroh7444/5b4f4fdfbde575632d0f6c42/dampakliterasi-media-digital-di-kalangan-mahasiswa

Brannen, J. (2005). Mixing methods: The entry of qualitative and quantitative approaches into the research process. International Journal of Social Research Methodology, 8(3), 173184. https://doi.org/https://doi.org/10.1080/13645570500154642

Herawati, D. . (2016). Penyebaran Hoax dan Hate Speech sebagai Representasi Kebebasan $\begin{array}{llll}\text { Berpendapat. } & \text { 2(2), 138-155. Remedia, Retrieved from }\end{array}$ http://halmaheraselatankab.go.id/pdf/pogja.pdf

Malmelin, N. (2010). What is Advertising Literacy? Exploring the Dimensions of Advertising Literacy. Journal of Visual Literacy, 29(2), 129-142. https://doi.org/https://doi.org/https://doi.org/10.1080/23796529.2010.11674677

Nasrullah, R. (2014). Teori dan Riset Media Siber (Cybermedia). Kencana Media Group.

Palupi, D. H., \& Pambudi, T. S. (2006). Buku Advertising that Sells. Gramedia Pustaka Utama.

Sanna, A., Serafin, R., \& Maganetti, N. (2011). Lecture Notes in Computer Science (Including Subseries Lecture Notes in Artificial Intelligence and Lecture Notes in Bioinformatics). EHealth, 697-720. https://doi.org/https://doi.org/10.1007/978-3-642-19050-6_26

Slevitch, L. (2011). Qualitative and Quantitative Methodologies Compared: Ontological and Epistemological Perspectives. Journal of Quality Assurance in Hospitality and Tourism, 12(1), 73-81. https://doi.org/https://doi.org/https://doi.org/10.1080/1528008X.2011.541810

Sunaryo, R., Karo, S. ., \& Dita, R. (2018). Literasi Iklan dan Cara Belanja Sehat Siswa SMP di Jakarta Selatan. Jurnal ISIP: Jurnal IImu Sosial Dan IImu Politik, 15(2), 59. https://doi.org/https://doi.org/10.36451/j.isip.v15i2.19 
Surakarta, I. (2020). Pelatihan Penggunaan Hoax Buster Tools. 1(2), 119-134.

Virga, R. . (2017). Literasi Iklan Rokok Dan Perilaku Konsumtif Remaja Melalui Pemberdayaan

$\begin{array}{llll}\text { Remaja Masjid. } & \text { Profetik: Jurnal Komunikasi, }\end{array}$

https://doi.org/https://doi.org/10.14421/pjk.v9i2.1201 